\title{
The Threshold for Under-Reinforced Concrete Sections Proposed by ACI 318, EC 2 and BS 8110
}

\author{
Panjehpour $^{1, *}$, Shahryar Sorooshian ${ }^{2}$, Deepak T. J. ${ }^{3}$ \\ ${ }^{1}$ Centre for Advanced Concrete Technology, Department of Civil Engineering, INTI International University, Nilai, Malaysia \\ ${ }^{2}$ Department of Business Administration, University of Gothenburg, Gothenburg, Sweden \\ ${ }^{3}$ Department of Civil Engineering, Manipal International University, Nilai, Malaysia
}

Received June 6, 2021; Revised July 12, 2021; Accepted August 22, 2021

\section{Cite This Paper in the following Citation Styles}

(a): [1] Panjehpour, Shahryar Sorooshian, Deepak T. J., "The Threshold for Under-Reinforced Concrete Sections Proposed by ACI 318, EC 2 and BS 8110," Civil Engineering and Architecture, Vol. 9, No. 6, pp. 1754-1758, 2021. DOI: 10.13189/cea.2021.090609.

(b): Panjehpour, Shahryar Sorooshian, Deepak T. J. (2021). The Threshold for Under-Reinforced Concrete Sections Proposed by ACI 318, EC 2 and BS 8110. Civil Engineering and Architecture, 9(6), 1754-1758. DOI: 10.13189/cea.2021.090609.

Copyright $(2021$ by authors, all rights reserved. Authors agree that this article remains permanently open access under the terms of the Creative Commons Attribution License 4.0 International License

\begin{abstract}
The ductile behavior of reinforced concrete (RC) cross-sections has always been desirable for building codes and standards. However, the threshold to distinguish ductile and brittle behavior of RC cross-sections proposed by building codes has yet to be evaluated [1-4]. This behavior mainly depends on the type of RC cross-section whether it is under- or over-reinforced. While there is not much research conducted on general comparison of the three codes of ACI 318-19, BS 8110 and Eurocode 2 (EC2) regarding design and analysis of RC structural elements, the specific detailed investigation on the threshold for under- and over-reinforced RC cross-sections has yet to be conducted. This article aims to determine the most accurate threshold used to distinguish under- and over-reinforced $\mathrm{RC}$ cross-sections amongst the three aforesaid codes by scrutinizing fundamentals and assumptions. A RC cross-section with strain distribution diagram over the section for the three statuses of under-reinforced, balanced, and over-reinforced cross-section is discussed in this research. A theoretical approach is adopted to compare the threshold through the depth of neutral axis of balanced steel concrete cross-sections. The method of calculation is associated with the maximum tensile strain of longitudinal steel bars at the cross-section. The depth of neutral axis is considered to be equal to effective depth of the cross-section multiple by a coefficient. This coefficient is the focus of the comparison. The coefficient is directly given as a number by BS 8110 and EC2. In ACI 318-19 there is no direct value given for the threshold, which
\end{abstract}

leaves no choice other than the accurate calculation of depth of neutral axis for the balanced reinforcement which is in form of an equation. The article concludes that ACI 318-19 provides the most accurate threshold to classify under- and over-reinforced RC cross-sections while EC2 provides the least accurate threshold. The accuracy of threshold proposed by BS 8110 is between those of ACI318-19 and EC2. The scope of this research is confined to singly- and doubly-reinforced concrete cross-sections with any shape using ordinary concrete.

Keywords Concrete Cross-Section,
Under-Reinforced, Over-Reinforced, Ductile Behavior

\section{Introduction}

Globalizations has brought up all comparison issues regarding methods and techniques adopted for the construction industry and building codes and standards have not been apart from it [5-7]. While there is not much research conducted on general comparison of the three codes of ACI 318-19, BS 8110 and Eurocode 2 (EC2) regarding design and analysis of RC structural elements, the specific detailed investigation on the threshold for under- and over-reinforced RC cross-sections has yet to be conducted. Under-reinforced RC cross-sections result ductile behavior which allows crack development in the 
building and consequently notifies the residents before the building collapses. This is the reason why under-reinforced cross-sections are in favor of those of over-reinforced which cause a sudden collapse. This indicates the importance of the research topic and its practicability. Ductile and brittle behavior of RC sections play a significant role in flexural design $[8,9]$. In recent years numerous studies have been conducted on flexural analysis and behavior of RC sections using ACI 318-19 [10-13], while the fundamentals and assumptions used to distinguish the ductile and brittle failure in flexural design of RC sections have left behind. Despite research conducted on flexural capacity of RC beam cross-sections using ACI $318[14,15]$ the comparison of ACI 318 , BS 81110 and EC2 is yet to be discussed by scrutinizing the fundamentals and assumptions made. Nevertheless, a few researches have discussed RC cross-sections design by comparing the three aforementioned codes from general aspects $[16,17]$. By investigating and analyzing a wide range of RC cross-sections varied in geometry, material property and reinforcement ratio, it was concluded that the difference of design strength between ACI 318 and BS 8110 are minor for flexural designs, moderate for axial compression designs and considerable for shear designs [18].

A comparative study conducted on BS 8110 and EC2 regarding the tensile and shear reinforcement required for design of RC beam cross-sections revealed that EC2 requires less amount of reinforcement in comparison to that of BS 8110 for both flexural and shear designs [19]. In prior research, BS 8110 and EC2 were compared for design and analysis of beam, but the research did not conclude in favor of either BS 8110 or EC2, and just stated that the approach of EC2 is less restrictive and more extensive than BS $8110[20,21]$. However, this conclusion seems to be valid for only part of EC2 as the shear design method proposed by EC2 using the concept of variable strut inclination restricts the users in terms of selection of appropriate truss model. Overall, the threshold to distinguish ductile and brittle behavior of RC cross-sections proposed by building codes has yet to be evaluated. This article aims to determine the most accurate threshold used to distinguish under- and over-reinforced RC cross-sections amongst ACI 318-19, EN 1992-1-1 (Eurocode2) and BS 8110.

\section{Materials and Methods}

In ductile or under-reinforced RC cross-sections, the tensile steel bars reach yield strain at loads lower than load at which the concrete reaches failure strain. It gives enough warning before failure, which is recommended by building codes. In brittle or over-reinforced RC sections the tensile steel bars yield after the concrete reaches the failure strain, and it occurs without early notice. Therefore, a threshold has been proposed by codes and standards to distinguish under- and over-reinforced RC sections, where the amount of tensile reinforcement is balanced. However, another threshold to classify the level of ductility of ductile cross-section is lacked in codes.

In this research, sequentially, a RC cross-section with strain distribution diagram over the section for the three statuses of $\mathrm{a}, \mathrm{b}$ and $\mathrm{c}$ respectively representing under-reinforced, balanced, and over-reinforced cross-section is scrutinized. Then, the research adopts a theoretical approach to compare the threshold proposed by the three aforementioned codes. The comparison is made through the depth of neutral axis of cross-sections in these three statuses. The method of calculation is associated with the maximum tensile strain of longitudinal steel bars at the cross-section. The depth of neutral axis is directly proportional to the aforementioned tensile strain.

In next step, the article considers the depth of neutral axis equal to effective depth of the cross-section multiple by a coefficient, and scrutinizes this coefficient which is directly given as a number by BS 8110 and EC2, and indirectly given in form of an equation in ACI 318-19. Graphs are plotted based on the values for the coefficients using the three codes and accuracy of the coefficient is discussed according to the assumptions made by the codes. Figure 1 indicates depth of neutral axis for under-, balanced and over-reinforced RC section. This cross-section has deliberately been selected to be in an irregular shape to cover all types of cross-sections.

In ductile or under-reinforced cross-sections, the tensile strain in steel bars is more than that of brittle or overreinforced, and for balanced steel sections is in between. Therefore, as shown in Figure $1, \varepsilon_{\mathrm{sa}}<\varepsilon_{\mathrm{sb}}<\varepsilon_{\mathrm{sc}}$ and consequently $\mathrm{x}_{\mathrm{a}}<\mathrm{x}_{\mathrm{b}}<\mathrm{x}_{\mathrm{c}}$ where $\mathrm{x}$ is the depth of neutral axis from the top concrete fibre. If $\varepsilon_{y}$ is the yield strain of steel bars, then the strain in steel bars in the three statuses of $\mathrm{a}, \mathrm{b}$ and $\mathrm{c}$ is as below. 

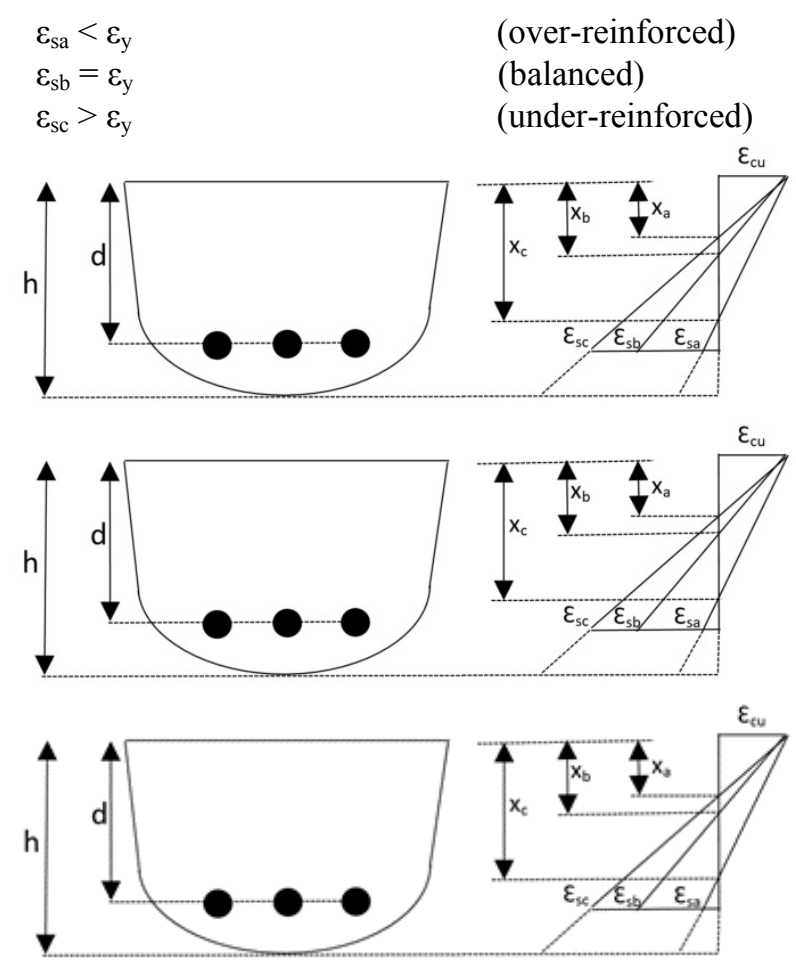

Figure 1. Depth of neutral axis for under-, balanced and over-reinforced RC cross-section

\section{Results and Discussion}

The plastic behavior of RC cross-sections made of ordinary concrete with the grade below $50 \mathrm{MPa}$ is considered in this research. The scope of this research doesn't include deep beams due to the nonlinear strain distribution over the RC cross-section [22-24]. According to Bernoulli's principle, ordinary beam cross-section which is a flat plane will remain flat plane after beam deformation and will not curve out-of-plane. Bernoulli's principle is applied to elastic, elasto-plastic and plastic behavior of material. Therefore, the strain distribution diagram over the cross-section is linear regardless of the shape of cross-section as shown in Figure 2. It is assumed that the beam is subject to downward load and therefore, the top fiber and bottom fiber in RC cross-section are under compression and tension, respectively.

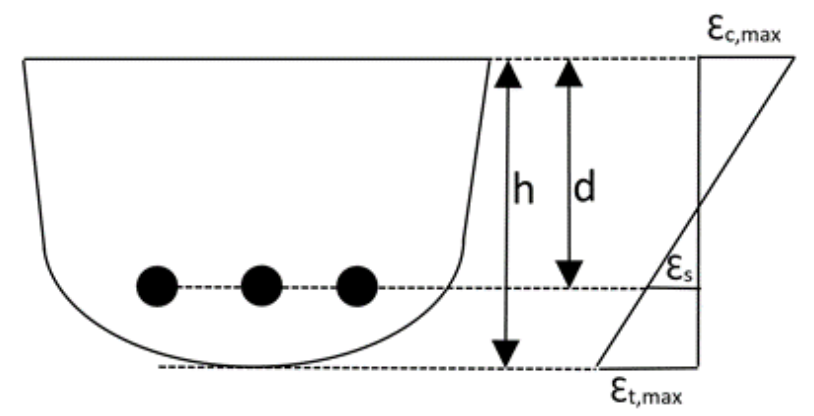

Figure 2. Linear strain distribution over irregular-shaped RC cross-section
Where,

$\varepsilon_{c, \max }:$ the maximum compressive strain at top fiber of concrete

$\varepsilon_{t, \text { max }}:$ the maximum tensile strain at bottom fiber of concrete

$\varepsilon_{S}:$ the tensile strain at reinforcement bars

In EC2 and BS 8110, the threshold to distinguish under- and over-reinforced RC cross-sections is the depth of neutral axis of the section for balanced reinforcement. In ACI 318-19 there is no direct value given for the threshold, which leaves no choice other than the accurate calculation of depth of neutral axis for the balanced reinforcement. In balanced steel status, $\varepsilon_{\mathrm{sb}}=\varepsilon_{\mathrm{y}}$

From Figure 2,

$$
\varepsilon_{\mathrm{cu}} / \varepsilon_{\mathrm{sb}}=\mathrm{x}_{\mathrm{b}} /\left(\mathrm{d}-\mathrm{x}_{\mathrm{b}}\right) \rightarrow \mathrm{x}_{\mathrm{b}}=\mathrm{d} \times \varepsilon_{\mathrm{cu}} /\left(\varepsilon_{\mathrm{cu}}+\varepsilon_{\mathrm{y}}\right)
$$

Where,

$\mathrm{x}_{\mathrm{b}}$ : depth of neutral axis from the top concrete fiber in a balance-reinforced RC cross-section

$\varepsilon_{c u}$ : the maximum strain at the extreme concrete compression fiber

$\varepsilon_{s b}$ : the tensile strain at the balanced steel bars

$\varepsilon_{y}$ : reinforcement yield stress

d: effective depth of cross-section

The equation below is proposed in this article.

$$
\mathrm{x}_{\mathrm{b}}=\alpha \times \mathrm{d}
$$

$\alpha$ : coefficient

The equation (1) is the same for doubly-reinforced RC cross-sections as the linear strain distribution diagram over the cross-section is the same. $\mathrm{x}_{\mathrm{b}}$ is the threshold to distinguish the under- and over-reinforced RC cross-sections. ACI 318-19 doesn't specify any value for $\alpha$ in equation (2) and the only valid method is adopting the direct equation (1) resulted from strain distribution over the cross-section. The equation (1) is for the calculation of $\mathrm{x}_{\mathrm{b}}$ and is independent from the shape of RC cross-section. However, EN 1992-1-1 (EC2) and BS 8110 simply propose a value for $\alpha$ instead of an equation as shown in Table 1.

The scope of this research is confined to ordinary concrete, and therefore the concrete grade above C55/67 falls out of the scope. According to ACI 318-19 (22.2.2.1), the maximum strain at the extreme concrete compression fibre shall be assumed equal to 0.003. Moreover, according to AC 318-19 (R22.2.2.21), the maximum concrete compressive strain at crushing of the concrete has been observed in tests of various kinds to vary from 0.003 to higher than 0.008 under special conditions. However, the strain at which strength of the member is developed is usually 0.033 to 0.004 for members of normal proportions, materials and strength. Assuming a common value for the yield strain of steel reinforcement equal to 0.002 and a range of $0.003-0.008$ with increment 
of 0.0005 for $\varepsilon_{\mathrm{cu}}$ the values of $\alpha$ are plotted in Figure 3.

According to the graph in Figure 3, the coefficient $\alpha$ increases from 0.60 to 0.80 when $\varepsilon_{\mathrm{cu}}$ increases from 0.003 to 0.008 . $\alpha$ is constantly 0.5 according to BS 8110 code, and 0.45 for ordinary concrete according to EC2. Therefore, $\alpha$ is calculated accurately based on equation (2) which is obtained from the linear strain distribution over RC cross-sections. $\alpha$ proposed by BS 8110 code is less accurate than that of ACI 318-19 but more accurate than that of EC2. There are two lines representing EC2 in Figure 3 as EC2 provides different values depending on the grade of the concrete.

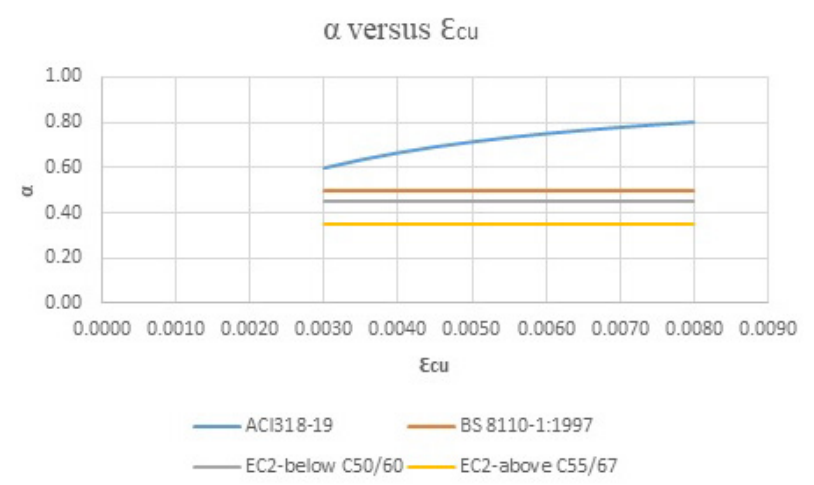

Figure 3. The values of $\alpha$ based on the three code

Table 1. Comparison of the coefficient $\alpha$ amongst the three codes

\begin{tabular}{|c|c|c|c|}
\hline Code & $\begin{array}{c}\mathrm{ACI} \\
318-19 \\
\end{array}$ & EN 1992-1-1 (EC2) & $\begin{array}{c}\text { BS } \\
8110-1: 1997 \\
\end{array}$ \\
\hline Clause & NA & cl.5.6.3 & cl. 3.4.4.4 \\
\hline \multirow{2}{*}{$\alpha$} & \multirow{2}{*}{$\varepsilon_{\mathrm{cu}} /\left(\varepsilon_{\mathrm{cu}}+\varepsilon_{\mathrm{y}}\right)$} & $\begin{array}{c}0.45 \text { (concrete strength } \\
\text { class } \leq \mathrm{C} 50 / 60 \text { ) }\end{array}$ & \multirow{2}{*}{0.5} \\
\hline & & $\begin{array}{l}0.35 \text { (concrete strength } \\
\text { class } \geq \text { C } 55 / 67 \text { ) }\end{array}$ & \\
\hline
\end{tabular}

The lower value of $\alpha$ indicates lower depth of neutral axis from the top concrete fiber in a balance-reinforced concrete cross-section $\left(\mathrm{x}_{\mathrm{b}}\right)$, and consequently greater tensile strain in tensile reinforcements. This results in a more ductile behavior of RC cross-section, which is in favor of all codes and standards. ACI provides the most accurate threshold to distinguish under- and over-reinforced RC cross-sections and EC2 provides the less accurate threshold while that of $\mathrm{BS} 8110$ is in between.

\section{Conclusions}

The thresholds to distinguish under- and over-reinforced RC cross-sections proposed by ACI 318-19, EN 1992-1-1 (EC2) and BS 8110 were scrutinized and compared in this article by adopting a theoretical approach. The comparison was made through the depth of neutral axis of cross-sections with balanced tensile reinforcement. The scope of the research included both singly- and doubly-reinforced RC cross-sections with any shape. The depth of neutral axis was considered to be equal to effective depth of the cross-section multiple by a coefficient. This coefficient is the focus of the comparison. The coefficient is directly given as a number by BS 8110 and EC2. In ACI 318-19 there is no direct value given for the threshold, which leaves no choice other than the accurate calculation of depth of neutral axis for the balanced reinforcement which is in form of an equation. The article concludes ACI 318-19 provides the most accurate threshold to distinguish the under- and over-reinforced RC cross-sections and EC2 provides the less accurate threshold while that of BS 8110 is in between. This research could be further developed for the classification of minor ductile and major ductile RC cross-sections as there is not yet any threshold in codes to distinguish the level of ductility of ductile cross-sections. In addition, further research could shed light on the range of ductility which is optimized and required for the construction and buildings.

\section{REFERENCES}

[1] Y. A. Priastiwia, I. Imranb, Nurojia, and A. Hidayata, "Behavior of ductile beam with addition confinement in compression zone," presented at the 2nd International Conference on Sustainable Civil Engineering Structures and Construction Materials 2014 (SCESCM 2014), 2014.

[2] C. G. Nogueira and I. D. Rodrigues, "Ductility Analysis of RC Beams Considering the Concrete Confinement Effect Produced by the Shear Reinforcement: a Numerical Approach," Latin American Journal of Solids and Structures vol. 14, no. 13, 2017. [Online]. Available: https://www.scielo.br/j/lajss/a/r3T3K3vZcmTp7Khj4sD9h $\mathrm{Kv} /$ ?lang=en.

[3] M. Moretti and T. P. Tassios, "Behavior and ductility of reinforced concrete short columns using global truss model," ACI Structural Journal, vol. 103, pp. 319-327, 05/01 2006.

[4] F. Accornero, A. Rubino, and A. Carpinteri, "Ductile-to-brittle transition in fibre-reinforced concrete beams: Scale and fibre volume fraction effects," Material Design \& Processing Communications, vol. 2, no. 6, p. 11, 2020. [Online]. Available:https://doi.org/10.1002/mdp2.12 7.

[5] Sutarno, Antonius, and Sumirin, "On the Analytical Models of Confined High-Strength Steel-Fiber Concrete," Civil Engineering and Architecture, vol. 9, no. 3, pp. 869-873, 2021, doi: 10.13189/cea.2021.090328.

[6] S. Sethi, "Corporate Codes of Conduct and the Success of Globalization," Ethics \& International Affairs, vol. 16, pp. 89-106, 08/30 2006, doi: 10.1111/j.1747-7093.2002.tb003 77.x.

[7] M. M. Darwish, A. Nejat, and T. Ghebrab. T. T. University. (2012). Globalization and the New Challenges for Construction Engineering Education. 
[8] M. Rakhshanimehr, M. R. Esfahani, R. Kianoush, B. Mohammadzadeh, and S. R. Mousavi, "Flexural ductility of reinforced concrete beams with lap-spliced bars," Canadian Journal of Civil Engineering, vol. 41, 07/01 2014, doi: 10.1139/cjce-2013-0074.

[9] B. Behnam and M. Al-Iessa, "Flexural Resistance Factors for Structural Ultra Lightweight Engineered Cementitious Composite Slabs," Civil Engineering and Architecture, vol. 9, no. 3, pp. 807-819, 2021, doi: 10.13189/cea.2021.09032 2 .

[10] J. Zhu, X. Guo, J. Kang, M. Duan, and Y. Wang, "Numerical and theoretical research on flexural behavior of steel-UHPC composite beam with waffle-slab system," Journal of Constructional Steel Research, vol. 171, p. 106141, 2020/08/01/ 2020, doi: https://doi.org/10.1016/j.jc sr.2020.106141.

[11] M.-Z. Wang, Y.-L. Guo, J.-S. Zhu, and X. Yang, "Flexural buckling of axially loaded concrete-infilled double steel corrugated-plate walls with T-section," Journal of Constructional Steel Research, vol. 166, p. 105940, 2020/03/01/ 2020, doi: https://doi.org/10.1016/j.jcsr.2020. 105940.

[12] M. Chen et al., "Flexural strength and ductility of moso bamboo," Construction and Building Materials, vol. 246, p. 118418, 2020/06/20/2020, doi: https://doi.org/10.1016/j.c onbuildmat.2020.118418.

[13] C. Barris, P. Sala, J. Gómez, and L. Torres, "Flexural behaviour of FRP reinforced concrete beams strengthened with NSM CFRP strips," Composite Structures, vol. 241, p. 112059, 2020/06/01/2020, doi: https://doi.org/10.1016/j.c ompstruct.2020.112059.

[14] E. I. Saqan, H. A. Rasheed, and R. A. Hawileh, "An efficient design procedure for flexural strengthening of RC beams based on ACI 440.2R-08," Composites Part B: Engineering, vol. 49, pp. 71-79, 2013/06/01/ 2013, doi: https://doi.org/10.1016/j.compositesb.2013.01.006.

[15] Z. He and F. Qiu, "Probabilistic assessment on flexural capacity of GFRP-reinforced concrete beams designed by guideline ACI 440.1R-06," Construction and Building
Materials, vol. 25, no. 4, pp. 1663-1670, 2011/04/01/2011, doi: https://doi.org/10.1016/j.conbuildmat.2010.10.005.

[16] S. A. M. Mourad M. Bakhoum, Maha M. Hassan, "Comparison of actions and resistances in different building design codes," Journal of Advanced Research, vol. 7, no. 5, pp. 757-767, 2016

[17] F. A. Malhas and A. Rahman, "A Comparison of the ACI and EC2 Codes Provisions for Flexural Deflection," ACI Symposium Publication, vol. 210, 2/1/2003, doi: $10.14359 / 12575$.

[18] S. Tabsh, "Comparison between reinforced concrete designs based on the ACI 318 and BS 8110 codes," Structural Engineering and Mechanics, vol. 48, 11/25 2013, doi: 10.12989/sem.2013.48.4.467.

[19] T. Nwofor, S. Sule, and D. Eme, "A Comparative Study of Bs8110 and Eurocode 2 Standards for Design Of a Continuous Reinforced Concrete Beam," International Journal of Civil Engineering and Technology, vol. 6, pp. 76-84, 05/01 2015 .

[20] C. U. Nwoji and A. I. Ugwu, "Comparative Study of Bs 8110 and Eurocode 2 In Structural Design and Analysis," Nigerian Journal of Technology, vol. 36, no. 3, pp. 758-766, 2017.

[21] S. O. Franklina and K. K. Mensahb, "A Comparative Study of EC2 and BS8110 Beam Analysis and Design in a Reinforced Concrete Four Storey Building," Journal of Basic and Applied Scientific Research, vol. 1, no. 12, 2011.

[22] V. D. Sabale, M. D. Borgave, and Joshi, "Non-Linear Finite Element Analysis of Deep Beam," International Journal of Engineering Research \& Technology, vol. 3, no. 5, 2014.

[23] N. K and P. M. Philip, "Nonlinear Analysis of Deep Beam Reinforced with Steel Bar and Laminating FRP on Steel Bar," International Journal of Science Technology \& Engineering, vol. 3, no. 2, 2016.

[24] A. A.-. Azzawi, A. H. Mahdy, and O. S. Farhan, "Finite element analysis of deep beams on nonlinear elastic foundations," Journal of the Serbian Society for Computational Mechanics, vol. 4, no. 2, pp. 13-42, 2010. 